\title{
ОСОБЕННОСТИ ОЦЕНКИ СТОИМОСТИ СТАНКОСТРОИТЕЛЬНОГО ПРЕДПРИЯТИЯ
}

\author{
Игорь кудимов
}

Приведены методические основы оценки действующего предприятия. Рассмотрены отраслевые особенности оценки станкостроительного бизнеса и основные подходы к этой оценке.

Современная рыночная экономика немыслима без знания ценовых и стоимостных показателей функционирования предприятий. Ответить на вопрос: «Что сколько стоит и почему?» поручено относительно новой отрасли знания - оценочной. Роль оценочной деятельности закреплена в федеральном законодательстве (Федеральный закон от 29 июля 1998 года № 135-ФЗ «Об оценочной деятельности в Российской Федерации»), который устанавливает условия проведения обязательной и добровольной оценки в интересах государства, собственников, акционеров, кредиторов, а также третьих лиц.

Типовые задачи оценки российского предприятия вообще и станкостроительного в частности сводятся к целям

Ключевые слова: оценка бизнеса, станкостроение, затратный, доходный и сравнительный подходы, недвижимое и движимое имущество, баланс, нематериальные активь кредитования в различных формах, акционерным целям (размещение дополнительных пакетов акций, принудительный выкуп акций миноритариев и т.д), обеспечения сделок купли-продажи имущества, а также фискальных целей государства. Надлежащий отчет оценщика обеспечивает аргументированность любой сделке, даже в случае отсутствия обязательной оценки. Но роль оценки имущества не ограничивается только обеспечением сделок.

\section{ОСОБЕННОСТИ ОЦЕНКИ БИЗНЕСА ДЛЯ ЦЕЛЕЙ СТАНКОСТРОЕНИЯ}

Современный имущественный комплекс станкостроительного предприятия состоит из недвижимого имущества (земля, здания, сооружения, недвижимое имущество по закону), движимого имущества (машины и оборудование), нематериальных активов (в том числе гудвилл - деловая репутация организации), иного имущества, денежных потоков и обязательств.

\section{Особенности станкостроительной отрасли и рынка станков}

Можно выделить несколько особенностей рынка станков (как важной составляющей части станкостроительного предприятия).

1. Отрасль машиностроения, характеризующаяся наукоемкостью и высокой технологичностью. Современный станок - это комплекс передовых достижений металлообработки, электроники и информационных технологий с уровнем вложенности, достигающим 22.

2. Высокая доля (до 90\%) импортных деталей, узлов, агрегатов, критических технологий.

3. Наличие запретов, ограничений и обременений, установленных законодательством стран-экспортеров на некоторые виды продукции. 
4. Необходимость значительных нематериальных активов (НМА) для успешного функционирования такого бизнеса. Величина НМА в стоимости станка может достигать 5-10\%.

5. Особенности технологического процесса предприятия отрасли характеризуются необходимостью наличия:

$\checkmark$ сертифицированной системы менеджмента качества CMK (стандарты ISO);

$\checkmark$ логистической системы менеджмента (эффективной цепи поставок комплектующих);

$\checkmark$ квалифицированного, авторизованного персонала.

6. Информационная насыщенность рынка нового оборудования.

7. Информационная «закрытость» вторичного рынка (бывших в употреблении, восстановленных и модернизированных станков).

8. Широкое применение лизинговых и иных финансовых инструментов.

9. Невысокий срок экономической жизни (срок, в течение которого имущество приносит прибыль) исходя из особенностей отрасли как наукоемкой и высокотехнологичной.

\section{Оценка действующего предприятия}

(бизнеса)

Методической основой оценки действующего предприятия является Федеральный стандарт оценки «Оценка бизнеса (ФСО № 8)», утвержденный Приказом Минэкономразвития России от 01 июня 2015 года № 326. В соответствии с этим документом процедура оценки включает в себя:

1. заключение договора на проведение оценки, включающего задание на оценку;

2. сбор и анализ информации, необходимой для проведения оценки;

3. анализ макроэкономической ситуации и ее влияния на предприятие;

4. анализ рынка объекта оценки;

5. описание оцениваемого предприятия;

6. анализ финансового состояния Общества;

7. применение подходов к оценке, включая выбор методов оценки и осуществление необходимых расчетов;

8. расчет рыночной стоимости предприятия с использованием выбранных подходов;

9. согласование (обобщение) результатов применения подходов к оценке и определение итоговой величины стоимости объекта оценки;

10. итоговое заключение о величине рыночной стоимости объекта;

11. составление отчета об оценке.
Акцентируем свое внимание на выборе подходов и методов оценки, так как именно на этом этапе необходимо учитывать все особенности отрасли в целом и оцениваемого предприятия в частности.

Оценка бизнеса традиционно может осуществляться на базе трех подходов:

$\rightarrow$ затратного подхода (оценка на основе активов);

$\rightarrow$ доходного подхода;

$\rightarrow$ сравнительного подхода (рыночного подхода).

\section{Затратный подход}

Суть данного подхода заключается в том, что все активы предприятия (здания, машины, оборудование, запасы, дебиторская задолженность, финансовые вложения и т.д.) оцениваются по рыночной стоимости. Далее из полученной суммы вычитается стоимость обязательств предприятия. Итоговая величина показывает рыночную стоимость собственного капитала предприятия. Для расчетов используются данные баланса предприятия на дату оценки (либо на последнюю отчетную дату). Проводится корректировка счетов баланса. Рассчитывается остаточная восстановительная стоимость основных фондов, рыночная стоимость объектов недвижимости.

Затратный подход рекомендован для предприятий, имеющих значительные материальные активы, что полностью совпадает с одной из особенностей рассматриваемой отрасли.

\section{Доходный подход}

Исходя из названия подход используется для оценки предприятий с устойчивыми положительными денежными потоками.

\section{Сравнительный подход}

Сравнительный подход базируется на рыночной информации и учитывает текущие действия продавца и покупателя. Данный подход предусматривает использование информации по открытым компаниям, акции которых котируются на фондовом рынке, такая информация может использоваться в качестве ориентиров и при оценке компаний закрытого типа. Преимущество данного подхода заключается в использовании фактической информации, а не прогнозных данных, имеющих известную неопределенность. Сравнительный подход определяет уровень стоимости как неконтрольного, так и контрольного пакета акций, позволяющего полностью управлять предприятием.

Далее мы считаем необходимым привлечь внимание читателей к следующим особенностям рассматриваемого сегмента рынка (пп. 4 и 5). 


\section{ОЦЕНКА НЕМАТЕРИАЛЬНЫХ АКТИВОВ (НМА)}

Разработка современного станка требует реализации соответствующих научных и технологических достижений. Сегодня стоимость научных разработок в оборудовании достигает $10 \%$. Передача прав на программное обеспечение, ноу-хау, действующих сертификатов СМК и др., как правило, осуществляется на основе отдельных договоров с соответствующими поставщиками. Оформленные и учтенные в бухгалтерском балансе в установленном порядке ноу-хау, патенты, лицензии, сертификаты СМК и др. служат активом предприятия и напрямую положительно влияют на величину собственного капитала компании. Следует отметить необходимость оценки гудвилла, торговой марки предприятия. Данная тема заслуживает отдельной статьи.

\section{ОЦЕНКА ОРГАНИЗАЦИИ ТРУДА}

Различные аспекты организации труда (квалификация персонала, логистические процедуры, упомянутые выше), в силу своей природы не являются объектом гражданских прав, не могут отчуждаться и поэтому не подлежат самостоятельной оценке. Однако можно констатировать их хоть опосредованное, но значительное положительное влияние на интегральные показатели деятельности станкостроительного предприятия, такие как, например, EBITDA.

Таким образом, мы кратко рассмотрели основные этапы и особенности оценки станкостроительного предприятия. Более подробная информация содержится в следующих нормативных материалах и работах [1-7].

\section{ОЦЕНОЧНЫЕ ТЕХНОЛОГИИ КАК СРЕДСТВО ПОВЫШЕНИЯ ЭФФЕКТИВНОСТИ УПРАВЛЕНИЯ ПРОИЗВОДСТВОМ}

Рассмотрим также и возможные нетрадиционные аспекты использования оценочных технологий.

Все российские станкостроительные заводы были возведены в советские времена, что определяет как преимущества, так и недостатки их функционирования в современных рыночных условиях. Любой эффективный менеджер заинтересован, с одной стороны, в повышении реальных доходов, а с другой стороны - в снижении текущих расходов. В подавляющем большинстве случаев при налаженном корректном учете финансовых результатов структура расходов для руководства предприятия ясна. Ясна также и его интегральная доходность, которая обеспечивается функционированием предприятия, его активами, пассивами и человеческим потенциалом. Однако этой информации бывает недостаточно для разработки управленческих мероприятий по повышению эффективности, так как менеджменту неизвестна текущая (не бухгалтерская!) структура стоимости бизнеса и, соответственно, экономическая роль каждого элемента, подлежащего учету в общей стоимости. Такое знание дает оценка действующего предприятия, которая позволяет не только исследовать статику такого процесса, но и при дополнительной информации выделить структуры стоимости с низкой, нулевой или отрицательной эффективностью.

\section{ЗАКЛЮЧЕНИЕ}

Оценка стоимости станкостроительного предприятия является необходимым условием его инвестиционной привлекательности, конкурентоспособности и развития в условиях рыночной экономики.

\section{ЛИТЕРАТУРА}

1. Федеральный стандарт оценки «Общие понятия оценки, подходы к оценке и требования к проведению оценки (ФСО № 1)». Утвержден приказом Минэкономразвития России от 20 мая 2015 года № 297;

2. Федеральный стандарт оценки «Цель оценки и виды стоимости (ФСО № 2)». Утвержден приказом Минэкономразвития России от 20 мая 2015 года № 298;

3. Федеральный стандарт оценки «Требования к отчету об оценке (ФСО № 3)». Утвержден приказом Минэкономразвития России от 20 мая 2015 года № 299.

4. Федеральный стандарт оценки «Оценка бизнеса (ФСО № 8)». Утвержден Приказом Минэкономразвития России от 01 июня 2015 года № 326. Настоящий Федеральный стандарт оценки развивает, дополняет и конкретизирует требования и процедуры, установленные ФСО №1-3, и является обязательным к применению при оценке бизнеса;

5. Десмонд Г.М., Ричард Э.К. Руководство по оценке бизнеса. - М.: РОО, 1996.

6. Григорьева Т.И. Финансовый анализ для менеджеров: оценка, прогноз: учебник для магистров / 2-е изд., перераб. и доп. - М.: Юрайт; ИД Юрайт, 2012. 462 c.

7. Грязнова А.Г., Федотова М.А. Оценка стоимости предприятии (бизнеса). - М.: Интерреклама, 2003. 543 c.

\section{кудимов Игорь Степанович -}

генеральный директор АНО «Центр независимой оценки», член Методического совета Российского общества оценщиков 


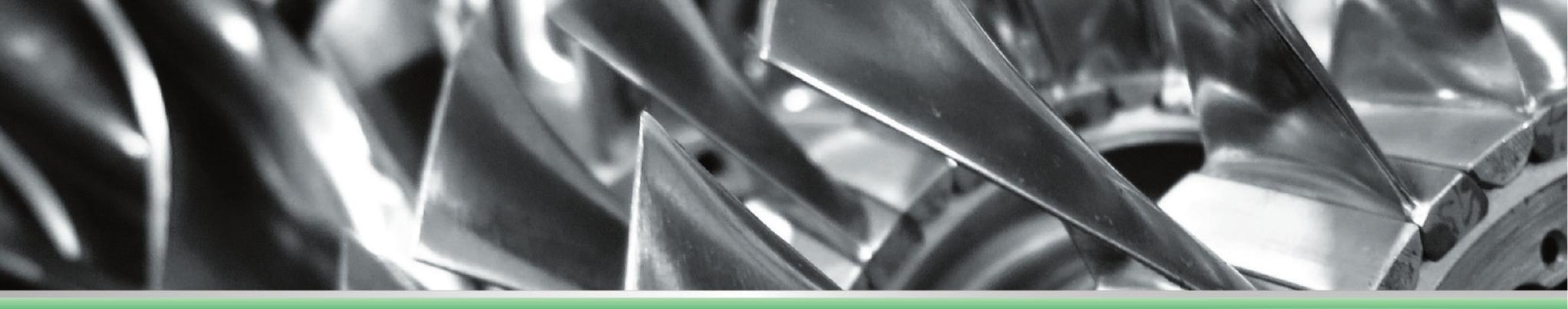

\section{ТЕХНОЛОГИЯ CASTROLXBB}

БЕЗОПАСНОСТЬ БЕЗ НОМПРОМИССОВ

БЕЗ БИОЦИДОВ БЕЗ БОРА

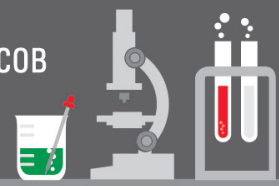

Более 100 лет Castrol производит и поставляет высокозффективные смазочные материалы и технологические жидкости для промышленного оборудования. Инженеры Castrol осознают, накую ценность для машиностроительных предприятий представляет возможность высококачественной, безопасной экономичной обработки металлов. Именно поэтому наши специалисты разработали широкий спектр смазочно-охлаждающих жидкостей, включая две новые линейки на базе инновационной технологии Castrol XBB.

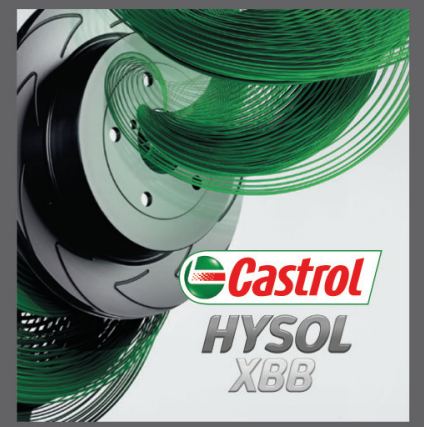

Частицы обрабатываемого металла могут приводить К нарушению стабильности эмульсии как сами по себе, так и являясь очагами для размножения микроорганизмов. Новые продукты линейки Hysol содержат компоненты, позволяющие сохранить стабильность жидкости длительное время даже в таких условиях

\section{Преимущества}

- Не содержит хлор, бор и выделяющие формальдегид вещества

- Содержит компоненты, способствующие улучшению качества по-

верхности наряду с увеличением стойкости инструмента

- Отличается высокой механической и биологической стабильностью

- Характеризуются низким вспениванием (при соблюдении рекомендаций для смешения эмульсии, учитывающих качество используемой воды)

- Обеспечивает отличное смачивание

- Не оказывает влияния на поверхности оборудования и оснастки

Спецификации и одобрения: Airbus: AIMS12-10-000 (technical specification); AIMS12-10-001 (material specification); Safran Group: D-180516-03944; BAMS 569-001 Version B;

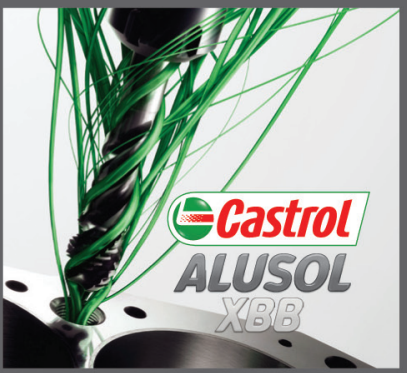

При обработке алюминия и его сплавов, включая авиационные, существует тенденция к образованию наростов на режущем инструменте и изменению его геометрии. Композиция линейки Alusol XBB, разработанная c целью увеличения срока службы инструмента, обеспечивает чистоту инструмента и деталей одновременно сулучшением качества обрабатываемой поверхности.

\section{Преимущества}

- Высокоэффективная полусинтетическая смазочно-охлаждающая жидкость

- Не содержит бор, хлор и выделяющие формальдегид вещества

- Компоненты, входящие в ее состав, способны улучшить эффективность обработки в сочетании с улучшением качества обрабатываемой поверхности

- Демонстрирует превосходную стабильность

Спецификации и одобрения: Safran Group: D-110416-03004

\section{СИНТЕТИЧЕСКИЕ СОЖ CASTROL SYNTILO}

Смазочно-охлаждающие жидкости Castrol с успехом используются ведущими мировыми производителями. Продукты линейки синтетических водосмешиваемых COЖ Castrol Syntilo по биостойкости и механической стабильности значительно превосходят жидкости с содержанием минерального масла.

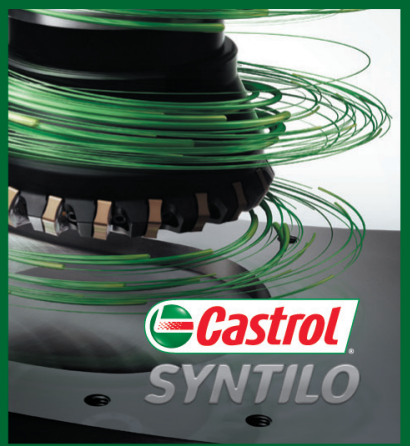

Высокоскоростная обработка приводит к экстремальным температурам на режущей кромке, иногда превышающим $1000^{\circ} \mathrm{C}$ Такие температуры негативно влияют как на деталь, так и на обрабатывающий инструмент. Технологии Syntilo позволяют охлаждать зону резания не хуже воды, одновременно смазывая режущую кромку как традиционная эмульсия.

\section{Преимущества}

- рН-нейтральны, не содержат бор и выделяющие формальдегид вещества

- Специально разработаны с учетом применения в большинстве операций обработки резанием различных металлов, включая авиационные сплавы титана и алюминия

- Отличные смазывающие и охлаждающие свойства

- Низкая склонность к вспениванию даже при высоких давлениях подачи и смешивании с мягкой водой

- Значительно более стойкие к биопоражению по сравнению с СОЖ с содержанием минерального масла 